\title{
Cause of egg mortality in azuki bean weevils (Callosobruchus chinensis): physical or chemical?
}

\author{
Koichi Fujii
}

Published online: 3 March 2009

(C) The Society of Population Ecology and Springer 2009

Erratum to: Popul Ecol (2009) 51:99-104

DOI 10.1007/s10144-008-0098-0

The original version of this article unfortunately contained an error. The second part of Eq. 2 on p. 101 should read $=1-k x(-0.05 x+1),(k \leq 0.2)$

The online version of the original article can be found under doi:10.1007/s10144-008-0098-0.

K. Fujii ( $\bowtie)$

Graduate School of Life and Environmental Sciences,

The University of Tsukuba, 1-1-1 Tennnodai, Tsukuba,

Ibaraki 305-8572, Japan

e-mail: fujiiko@pe.ies.life.tsukuba.ac.jp 